\title{
Professor Han-Jong Rim (1931-2021): A Life of Parasitology and Parasite Control in This Wormy World
}

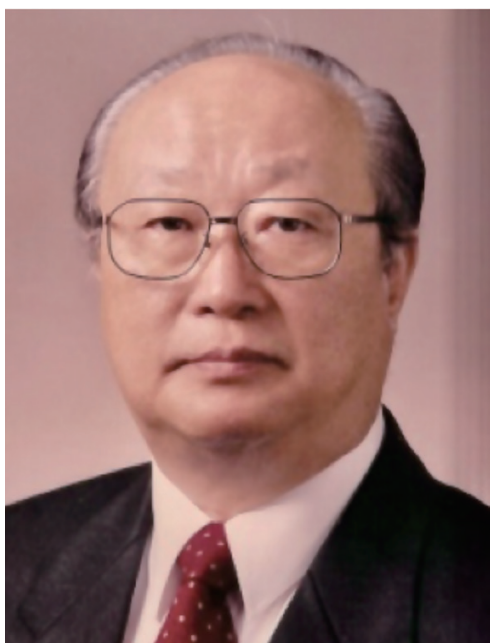

Professor Han-Jong Rim

(1931-2021)

Professor Han-Jong Rim, a lifetime member of the Korean Academy of Sciences and Technology, passed away on February 16, 2021. Professor Rim was an honorary member of the Korean Society for Parasitology and Tropical Medicine. He was a leading parasitologist in Korea, who devoted his life to research and eradication of parasites. He was born in Eumseonggun, Chungcheongbuk-do in 1931. In his second year of high school he won the Presidential Prize for discovery and exhibition of nine species of frog parasites at the National Science Exhibition (1949), in the first anniversary of the establishment of the Korean government. He has walked only a single path in parasitology his entire life with a sense of vocation.

After graduation from Seoul National University College of Medicine, Seoul, Korea in 1957 and becoming the first Doctor of Philosophy (Ph.D) in Parasitology in Korea (1963), he started as a full-time lecturer at Seoul National University College of Medicine and served as Assistant Professor and Associate Professor. In 1973, he founded the Department of Parasitology at Korea University College of Medicine, Seoul, Korea, awarded from the Korean Academy of Sciences in 1987, and served as the Head Professor and Director of the Tropical Endemic Disease Research Institute until retirement in 1997. He then served as the President of the Korea Association of Health Promotion from 1994 to 2000. Professor Rim served as a member of an Advisory Committee for parasitic diseases of WHO (1986-2000), and afterward contributed to international collaborative projects for parasite control as a medical specialist of the NGO Good Neighbors International (20072012).

In 2019, the Korea Development Institute (KDI) greatly impressed Professor Rim by selecting him as a great person who helped development of today's Korea for 70 years since the founding of the Republic of Korea. What he has devoted his life to is the fight against these parasitic diseases, and in the end, he succeeded in eliminating chronic diseases such as liver fluke, lung fluke infections, and neurocysticercosis. In particular, the immortal achievement of improving the quality of human life by developing praziquantel, a representative anthelmintic, with Shinpoong Pharmaceutical Company, Korea, a drug that can heal poor and neglected people around the world with only a few dollars, is engraved vividly in the minds of all parasitologists. Professor Rim discovered three new species of parasites in his lifetime, and Taenia asiatica Eom \& Rim (1993) is one of them.

Looking back, when the mass stool examination project in Korea was abolished in 1995, Professor Rim retired at the age of 65 , but still did not stop his activities and started global activities for parasite control as the President of the Korea Association of Health Promotion. After then, until 2009, he visited small villages in China, Laos, and Tanzania and poured all his last strength into exterminating parasites, and finally, when he became dependent on a cane, the giant's lifelong footsteps stopped. The great teacher of parasitology deserves generous praise as a pioneer who devoted his life to the promotion of global health, and who endlessly inspires many younger scientists, but when I met him last year he just said calmly, "I have become a person who cannot walk alone now."

The life of the great teacher has ended, and sorrow reaches 
the sky. And when it's finally time to say goodbye, white snow with a heart of remembrance falls on the ground in silence. Goodbye dear Professor, you will be long remembered for your heartfelt devotion to the field of parasitology and parasite control in this wormy world.
Keeseon S. Eom

International Parasite Resource Bank, Department of Parasitology, Chungbuk National University College of Medicine, Cheongju 28644, Korea

(keeseon.eom@gmail.com) 